\title{
Introduction to the Digital Government and Business Process Management (BPM) minitrack HICSS'54
}

\author{
Andrea Delgado \\ Universidad de la \\ Republica, Uruguay \\ adelgado@fing.edu.uy
}

\author{
Aurelie Montarnal \\ IMT Mines Albi \\ Industrial, France \\ aurelie.montarnal@, \\ mines-albi.fr
}

\author{
Hernán Astudillo \\ Universidad Técnica \\ Federico Santa María, \\ Chile \\ hernan@inf.utfsm.cl
}

\author{
Cristina Cabanillas \\ Universidad de Sevilla, \\ Spain \\ cristinacabanillas@,us.es
}

\begin{abstract}
Digital Government (traditionally known as eGovernment) focuses on value delivery to citizens through information and communication technology (ICT) support for processes, activities and resources. Digital government's collaborative processes involve organizations (employees, technologies), partners (providers, consumers), and users (citizens, foreigners), leading to complex interactions within different $e$ Government models and available technologies. Business Process Management (BPM) constitutes a real asset for enhancing the services of an organization and their coordination, as well as the products that each actor of a virtual network delivers to meet clients' expectations (citizens, patients, etc.). Successful interorganizational process management within $e$ Government collaborative organizations will lead to better conceptual and technological integration, not only with each other but also with citizens and users in general. To this end, it is necessary to devise new ways to deal with the complexity of e-Government collaborative process definition, modeling, analysis, enactment and monitoring from various dimensions and points of view including theory, engineering, interoperability, agility, social aspects, etc.
\end{abstract}

\section{Introduction}

Digital Government (traditionally known as eGovernment) focuses on value delivery to citizens through information and communication technology (ICT) support for processes, activities and resources. Since business processes may span several organizations, they can be deployed both internally (intra-organizational processes) and externally (interorganizational collaborative processes).

Digital government's collaborative processes involve organizations (employees, technologies), partners (providers, consumers), and users (citizens, foreigners), leading to complex interactions within different e-Government models and available technologies [1]. Collaborative organizations need ways to define and provide support for their interorganizational processes in order to interact with each other in an easier, more secure and more adequate way, ensuring the quality of the results to the internal and the external users.

This support must fulfill both centralized and decentralized scenarios depending on the domain and the organizations involved, including the integration of their existing software and information systems for the exchange of data and the execution of business functions. Interoperability is a key challenge in this context. It is not only provided by technical means but also thanks to business-oriented approaches, such as Business Process Management (BPM) [2][3][4].

BPM constitutes a real asset for enhancing the services of an organization and their coordination, as well as the products that each actor of a virtual network delivers to meet clients' expectations (citizens, patients, etc.). The BPM lifecycle embraces several phases that aim for a continuous process improvement, including process discovery and modeling, process analysis, process re-design, and process monitoring. Moreover, the deployment of a BPM approach in a sensitive eGovernment context often faces critical barriers, such as change management and a potential discouragement when it comes to modeling complex organizational behaviors.

The "Digital Government and BPM" minitrack focuses on digital government with a perspective on collaborative processes. New ideas on how to deal with the definition, modeling, enactment, monitoring and analysis of e-government collaborative processes will enable ways of improving the e-government experience for both organizations and citizens, taking into account conceptual, technological, interoperability, agile, and 
social dimensions. We invited and selected papers that deal with any aspect involved in the identification, design, analysis, implementation, enactment, integration, operation, evaluation, performance and use of BPM principles and existing/emerging BPM approaches for discussing inter-organizational process models, architectures, ICT integration and support, as well as case studies on the application of BPM to eGovernment scenarios.

\section{Sessions}

At this year's conference, the minitrack is organized in one session with two papers in it.

First, "Design and development of Smart Contracts for E-government through Value and Business Process Modeling" by Gómez et. al. presents an approach to design and develop smart contract-based services for egovernment. The integration of blockchain technologies [5] in the processes that make up e-government services is a challenge that many governments are undertaking. The paper presents a methodological and technical proposal that includes the definition of a model-based domain specific language (DSL) for developing smart contracts, and the relationships between smart contracts and $\mathrm{e}^{3}$ value (for modeling value exchange between interactions) and BPMN business process models, as well as corresponding tool support. The methodological approach focuses on specifying high level models such as BPMN or e3value to discuss contracts with business stakeholders and from these models generating a skeleton of technical smart contracts and services, by means of model to model (M2M) transformations. The technical approach includes an existing modeling toolkit where the DSL named $\mathrm{SmaC}$ for smart contracts development is integrated, as well as the generation of. The application of the approach is illustrated with an example corresponding to a real scenario on the electronic auctions used by the Spanish Government.

Then, "Towards compliance requirements modeling and evaluation of E-government interorganizational collaborative business processes" by González \& Delgado proposes an approach for specifying and evaluating compliance requirements for inter-organizational collaborative business processes for e-government. Business process compliance requirements [6] are becoming increasingly important for processes to be compliant with regulations and laws, among others, which is mandatory in an e-government environment where these processes are to be transparent to citizens and subject to public audits. The proposal envisions a step by step process for managing compliance requirements from business process modeling to process execution and evaluation. The paper focuses on modeling compliance requirements for business processes connecting them with BPMN 2.0 models, and the post-mortem evaluation of this specification based on process execution traces by means of process mining techniques in order to detect compliance violations. It also presents a model-based (DSL) named Compliance Requirements Modeling Language (CRML) and its relationships with BPMN 2.0 elements, a Compliance Requirements Model (CRM) specific for business processes, and an initial view on the post-mortem compliance evaluation with process mining. The application of the approach is illustrated with an e-Government scenario from the Uruguayan eGovernment Interoperability platform.

\section{References}

[1] Delgado, A., González, L., Calegari D., "Towards setting up a collaborative environment to support collaborative business processes and services with social interactions," in Service-Oriented Computing (ICSOC) Workshops \& Satellite Events, Rev. Selected Papers, pp. 308-320, Springer, 2017. [2] Van der Aalst, W.M.P., ter Hofstede, A., Weske, M., Business Process Management: A Survey, In: International Conference on Business Process Management, Springer, 2003 [3] Dumas M., La Rosa M., Mendling J., Reijers H., Fundamentals of Business ProcessManagement ISBN 978-3662-56508-7, Springer-Verlag, 2nd. Edition, 2018.

[4] Weske, M. Business Process Management: concepts, languages, architectures. ISBN 978-3-662-59431-5 SpringerVerlag, 3rd edition, 2019

[5] Crosby, M., Pattanayak, P., Verma, S., Kalyanaraman, V. Blockchain technology: Beyond bitcoin. Applied Innovation, 2(6-10), 71, 2016.

[6] Hashmi, M., Governatori, G., Lam, H.-P., Wynn, M. T. Are we done with business process compliance: state of the art and challenges ahead, Knowledge and Information Systems, vol. 57, pp. 79-133, 1, 2018. 